Pure \& Appl.Chem., Vo1.54, No.5, pp.987-1004, 1982. Printed in Great Britain.
0033-4545/82/050987-18\$03.00/0

Pergamon Press Ltd. ○1982 IUPAC

\title{
RING INVERSION AND BOND SHIFTING ENERGETICS IN SUBSTITUTED CHIRAL CYCLOOCTATETRAENES
}

\author{
Leo A. Paquette \\ Department of Chemistry, The Ohio State University, Columbus, Ohio 43210, USA
}

\begin{abstract}
In this lecture, an account is presented of new methodology which permits quantitative assessment of ring inversion and bond shifting barriers within [8] annulene derivatives. With optically active cyclooctatetraenes in hand, it suffices to determine the overall racemization rate and to obtain independent experimental measurement of one additional rate constant for complete numerical definition of their dynamic parameters. The antiaromatic nature of planar delocalized cyclooctatetraenes is analyzed and compared in magnitude to the overall conformational energetics of these systems.
\end{abstract}

The sequence of historical events which include (a) Willstätter's initial synthesis (19111913) of cyclooctatetraene (COT), (b) Hickel's proposition (1937) that this $4 \mathrm{n}$ system should be characterized by unfavorable $\pi$-electron delocalization, ${ }^{2}$ and (c) Reppe's development (1948) of a process which lends itself to large scale commercial production of $\mathrm{COT}^{3}$ has caused this hydrocarbon to become a target of intense experimental and theoretical scrutiny. ${ }^{4}$ The considerable attention commanded by cyclooctatetraene is, in large part, the result of its position as the smallest nonplanar [4n] annulene. ${ }^{\text {As a direct }}$ consequence of its ground state tub conformation and alternating single and double bonds, the COT ring system is capable of three fundamental structural changes. The first of these processes, termed ring inversion (RI), relates exclusively to conformational mobility and is isodynamical. ${ }^{7}$ While flexing of the parent COT merely regenerates the starting material, similar conversion of $\underset{\sim}{I}$ to $I_{\sim}^{\prime}$ leads to production of the enantiomer, presumably via planar

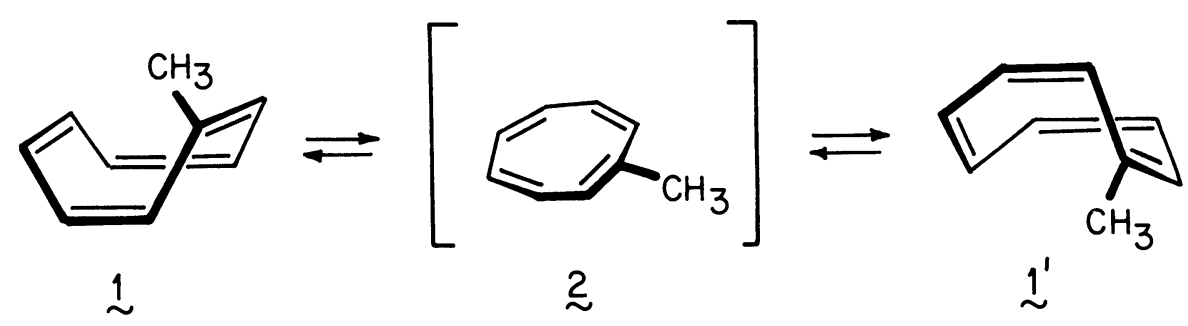

alternate transition state 2 . Were $\frac{1}{2}$ optically active, net racemization would therefore accompany this framework equilibration.

Cyclooctatetraenes are also capable of bond shifting (BS), a process which has usually been characterized by somewhat higher energy demands. ${ }^{7-13}$ These equally isodynamical structural alterations, generally viewed as mediated by planar-delocalized transition states, e.g. $3,7,8,12$ should also result in the racemization of chiral COT's. Of course, this event is dependent upon the ability of $z$ to produce both $\frac{1}{\sim}$ and $I^{\prime}$, an entirely plausible assumption (unsubstituted 3 has $D_{8}$ h symmetry). Transition state $\widetilde{3}$ constitutes a particularly elusive species $^{13}$ which should $\bar{b}$ e endowed with "antiaromatic" $\pi$-electron delocalization. Remaining pivotal questions deal with whether planar 3 is truly involved and, if so, to what degree it is destabilized. One may therefore inquire of 3 the true nature of its geometry, the extent of eight-membered ring distortion, if any, which may occur with alteration in peripheral substitution, and, most importantly, the magnitude of its resonance 

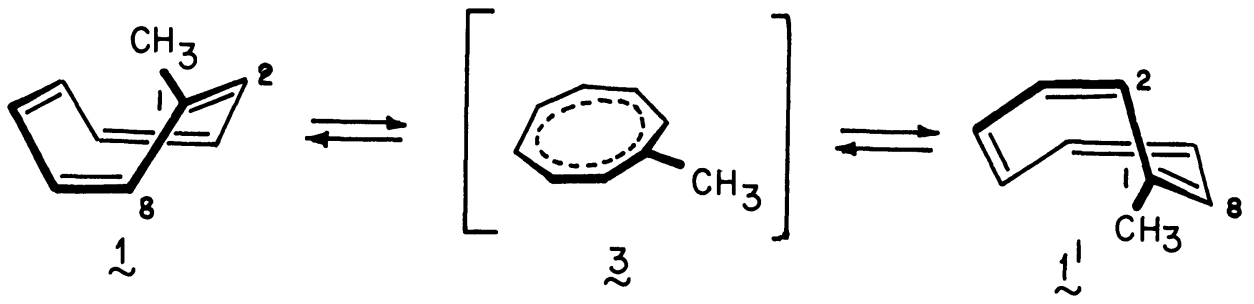

energy (negative or positive). The RE value for 3 cannot be zero, since this would ir principle equate the species with nonaromatic 2 from which it is experimentally distinguishable. Thus, to the extent that the hypothetical structures 2 and 3 are accurate, then the difference between the activation enthalpies for RI and BS in any COT will directly provide a value of the RE for the planar delocalized structure corresponding to 3 .

Isomerization with formation of valence tautomeric bicyclo[4.2.0]octatrienes comprises the third dynamic process available to cyclooctatetraenes. ${ }^{14}$ This structural equilibrium is unrelated to the two preceding phenomena since ring flattening is not required and racemization is not at issue. However, the synthetic value of conversions typified by $4 \rightarrow 1$

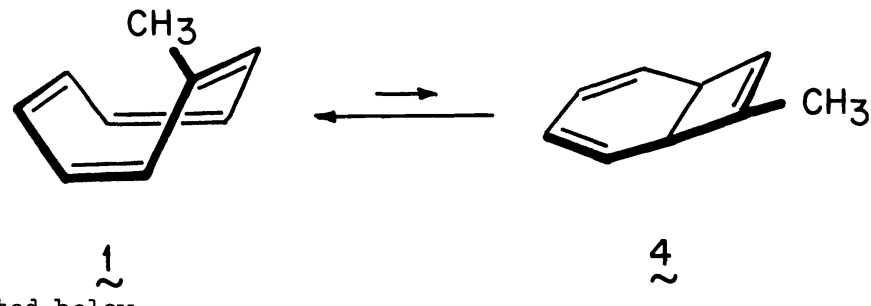

is to be illustrated below.

Prior to the new methodology to be described for the assessment of these questions, studies of $\mathrm{BS}$ and RI phenomena within selected COT's had earlier been carried out using variable temperature NMR spectroscopy. By substituting a COT carbon atom by ${ }^{13} \mathrm{C}$ and examining the fine structure of the resulting ${ }^{1}{ }^{3} \mathrm{C}$ satellites, Anet was able to observe temperature dependence. ${ }^{8}$ Line shape analysis of these spectra provided an estimate of $\Delta \mathrm{H}^{ \pm} \mathrm{BS}$ ( 13.9 $\mathrm{kcal} / \mathrm{mol})$. Attachment of a sidechain possessing a chiral center generates diastereomers whose interconversions have been subject to spectroscopic examination. ${ }^{8}$ Oth and his collaborators have performed similar elegant NMR studies on alkoxy cyclooctatetraenes. ${ }^{7,10}$ Thus, a real potential for stereoisomerism exists within this class of compounds, ${ }^{15}$ but these features remained to be fully exploited as a tool for the quantitative analysis of dynamic COT behavior.

\section{SHELF STABLE: [8]ANNULFNF. BOND SHIFT ISOMFRS}

Introduction of substituents onto the COT ring can be expected to impede the attainment of planar transition states, particularly if they are placed in a 1,2- or 1,3-relationship. In this connection, bond shift isomer 5 of methyl 2-methylcyclooctatetraenecarboxylate, which can be enriched to the $95 \%$ level by optical pumping, attains equilibrium with 6 at $-12^{\circ} \mathrm{C}$ with an energy barrier $\left(\Delta \mathrm{F}_{\mathrm{F}}=18.8 \mathrm{kcal} / \mathrm{mol}\right)$ appreciably larger than that for COT. ${ }^{8}$ The bond shift isomers of 7 , which are identical by virtue of symmetry, have

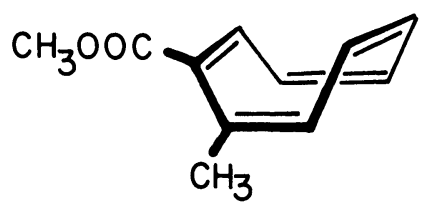

$\stackrel{5}{\sim}$
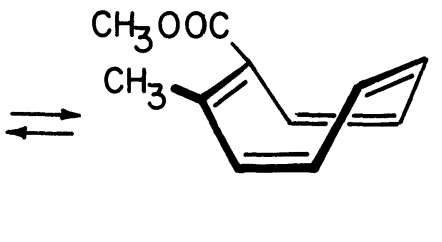

$\underset{2}{2}$

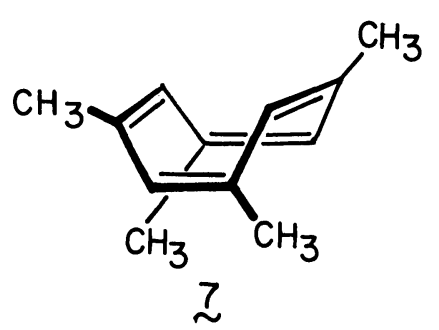

been reported to be separated by a still larger energy barrier $\left(\Delta \underline{G}^{ \pm}\right.$
$\left.120^{\circ} \mathrm{C}\right) .11$

The key observation for what is to follow was made in these laboratories by my former coworker James Photis approximately a decade ago. In the course of his examination of 
$\mathrm{Mo}(\mathrm{CO})_{6}$ - promoted skeletal rearrangements of unsaturated propellane systems, he noted that 8 was transformed in refluxing benzene solution to 9 and 10 in approximately equal amounts. 16 Furthermore, this pair of bond shift isomers could be easily separated, showed no evidence of mutual interconversion under ordinary laboratory conditions, and, in fact, underwent

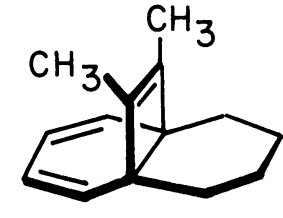

8

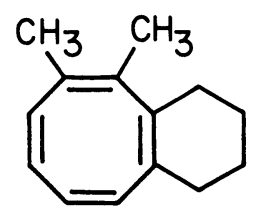

2

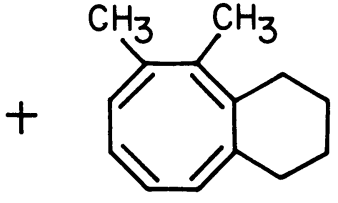

10

chemical transformations unique to their individual arrangements of double bonds.

Following this development, independent synthetic approaches to other pairs of shelf stable COT bond shift isomers were sought. In the first of these, the 1,2,3,4- (18) and 1,2,3,8tetramethylcyclooctatetraenes (15) were prepared in isomerically pure form and noted to be similarly subject to double bond fixation. In our original synthetic approach (Scheme I), 17 a new ring contraction protocol was devised which served to convert bicyclic sulfone 12 to diene 13. I8 Subsequent bromination-dehydrobromination transformed 13 into the unstable bicyclo[4.2.0]octatriene 14, whose ring opening was expected for orbital symmetry reasons to proceed under control of the cyclohexadiene ring to deliver 15 exclusively. Indeed, this reaction pathway was followed precisely, the $\underline{C}_{s}$ symmetry (i.e., meso nature) of 15 being apparent from its spectra and subsequent conve $\bar{r}$ sion to urazole 16 and irontricarbonyl complex 22. 17 When diene sulfone 17 was subjected to reductive desulfonyl:tion as before, 18 was produced as the predominant bond shift isomer. In contrast to 15 which is homogeneous within the limits of spectroscopic analysis, 18 was seen to be in equilibrium with appreciable amounts of bicyclic valence isomer 19 at room temperature (ratio 3:1). The presence in 18 of a twofold symmetry axis was borne out by its spectra, as well as those of 20 and 21 derived from it. 17 That the four contiguous methyl substituents in 15 and 18 serious $\widetilde{1 y}$ impede the attainment of planarity by the central eight-membered ring can be seen from the temperatures required for their interconversion (cf below). Notwithstanding the high level of peripheral strain, 15 and 18 were successfully reduced to the identical dianion (23), whose oxidation with iodine returned a mixture of the isomeric COT's.

\section{RESOLUTION OF CHIRAL CYCLOOCTATETRAENES AND ABSOLUTE CONFIGURATIONAL ASS IGNMENTS}

With tangible signs that the customarily high susceptibility of [8]annulenes for RI and BS are controllable, we proceeded to prepare 18 in optically active form with known absolute configuration. Initially, the sequence of steps outlined in Scheme I were viewed as unsuitable because of the inherent symmetry of 17 , the immediate precursor to the target tetramethyl COT. Consequently, the methodology depicted in Scheme II, which is based on the concept of early incorporation of optical activity, was developed. 19 , 20 Bromolactonization of levorotatory cis-dicarboxylic acid 24 resulted in highly efficient conversion to 25. Condensation of the derived acid chloride with $(\underline{R})-(+)-\alpha-$ methylbenzylamine afforded 26 which was subjected to $\mathrm{x}$-ray crystal structure analysis. As a direct result of the known absolute configuration of the amide sidechain in 26 , the absolute stereochemistry of the remainjng five chiral centers was easily deduced to be as shown in the formulas. Starting with optically pure (-) -24, levorotatory cyclobutene 28 was prepared. Monobromination-dehydrobromination of this hy $\widetilde{d r o c a r b o n}$ gave $(+)-18$ which must have the indicated stereochemistry since two chiral centers of the triad present in (-)-24 are not perturbed until the final ring opening.

The synthesis of $(+)-18$ just described has the disadvantage that it is inefficient at providing adequate quantities of the optically active [8]annulene. Alternatively, direct resolution of racemic 18 could not only in principle provide a more effective solution to the supply problem, but also permit the option of utilizing either Scheme I or Scheme II. For this purpose, we developed the (-)-endo-bornyltriazolinedione (29) reagent 21,22 which cycloadds to $( \pm)-18$ smoothly in hexane at $50^{\circ} \mathrm{C}$ to give the diastereomeric adducts 30 and 31 (Scheme III). Successive recrystallization of this mixture, or preferably high performance pressure chromatography, results in their mutual separation. Independent hydrolysisoxidation of the purified diastereoisomers permits convenient isolation of either enantiomer of 18. 20 The technique outlined in Scheme III has understandably evolved to become the method of choice for resolving [8]annulenes in this laboratory.

Our prior determination of the absolute stereochemistry of $(+)-18$ permitted direct assignment of configuration to the [8]annulenes produced in Scheme II $\widetilde{I}$. However, because the endo-bornyl moiety in (-)-29 emanates from d-camphor, its absolute configuration is well established. 22 Consequently, structural identification of a purified urazole diastereomer can likewise be achieved by $\mathrm{x}$-ray analysis. The direct resolution and absolute con- 
SCHEME I
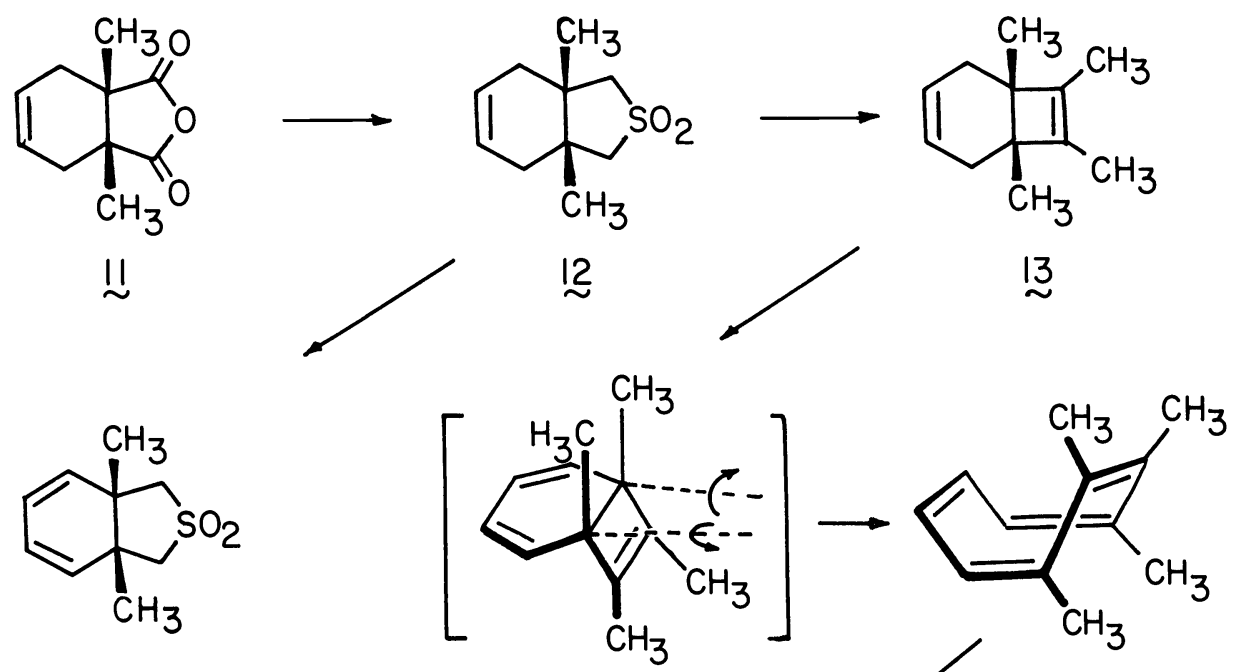

17

14

$\sqrt{2}$

$\mathrm{CH}_{3}$

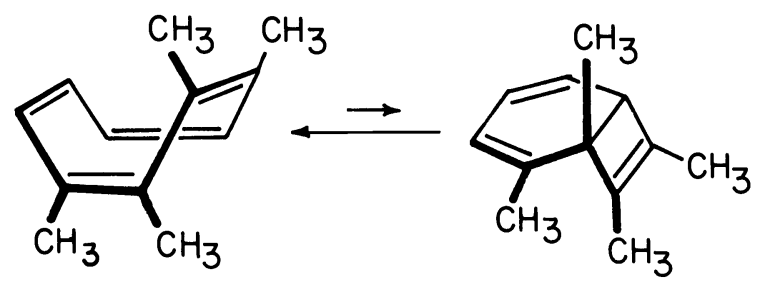

18

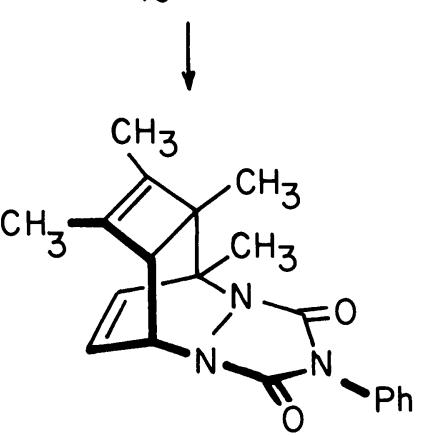

20
19

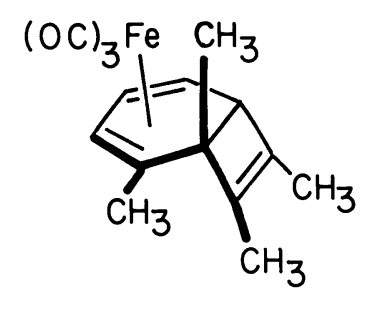

21

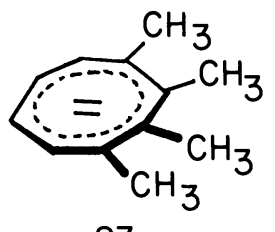

23 
SCHEME II
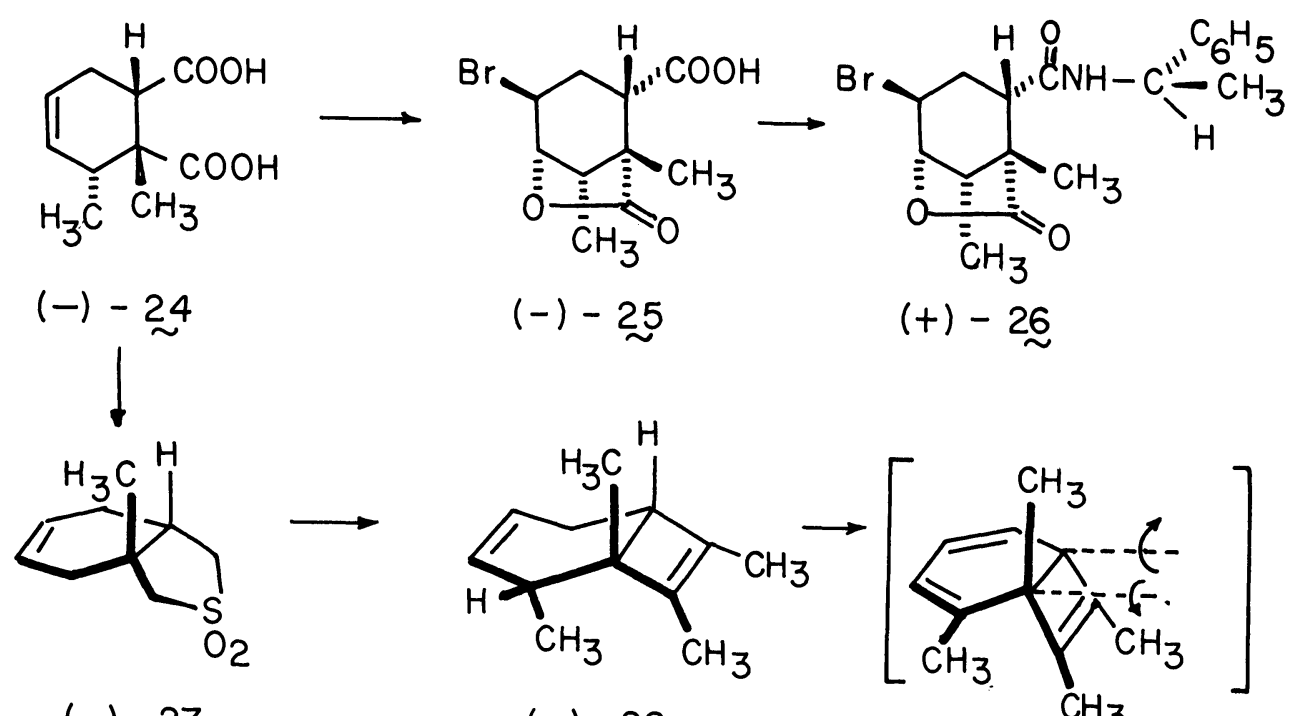

$(-)-27$

$(-)-28$

$19^{*}$

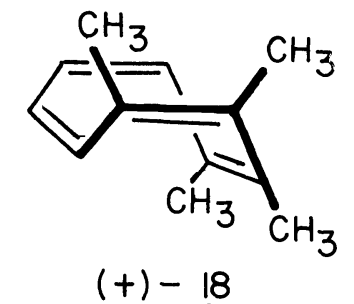

SCHEME III
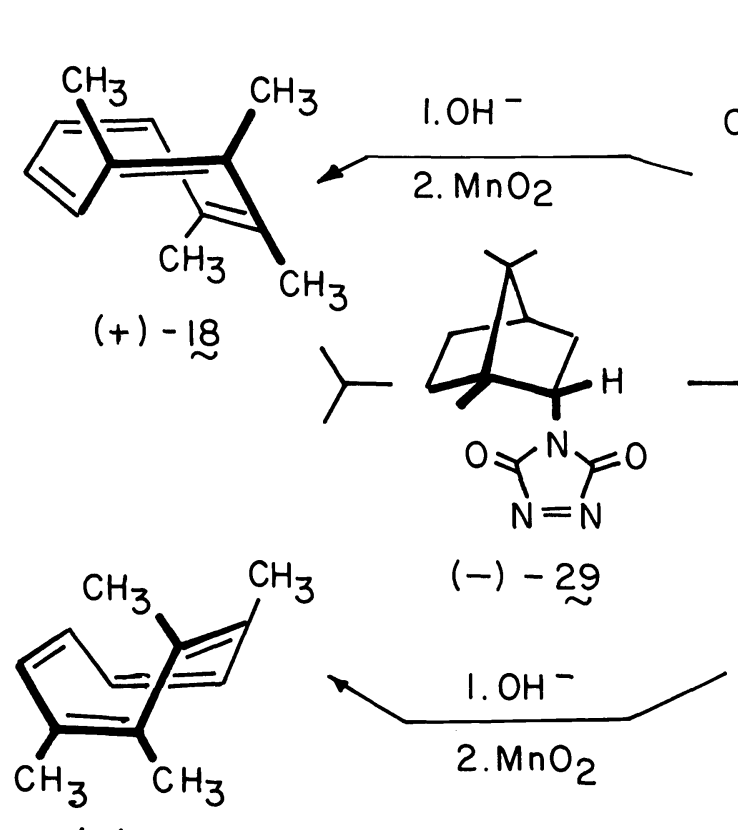

$(-)-18$
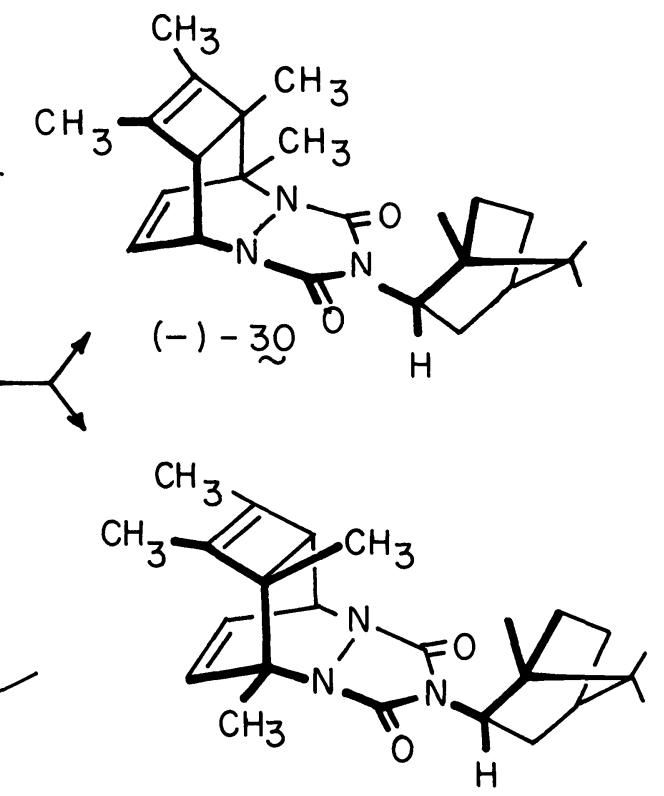

$(+)-31$ 
figurational assignments to 1,3-di-tert-butylcyclooctatetraene (32), which were achieved precisely in this manner, are illustrated in Scheme IV. ${ }^{23}$ An additional useful feature provided by the endo-bornylurazole adducts is the ease with which diastereomeric purity can be established by simple spectroscopic analysis. While our early efforts in this area were based upon chemical shift separations achieved by addition of such chiral auxiliaries as tris[3-(trifluoromethylhydroxymethylene)-d-camphorato] europium (III) ${ }^{23}$ and $(R)-(-)-1$, 1,1-trifluoro-2-(9-anthryl) ethanol, ${ }^{20}$ more recent work has shown that high field ${ }^{1} \mathrm{H}$ NMR $(\geq 300 \mathrm{MHz})$ is adequate to resolve the bornyl bridgehead methyl singles of the diastēereomers.

\section{SCHEME IV}

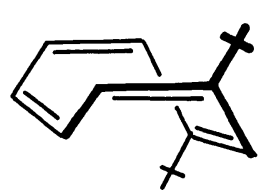

$(+)-32$

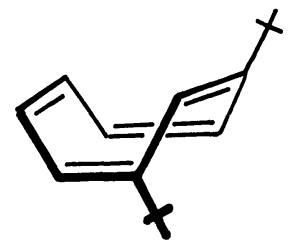

$(-)-32$
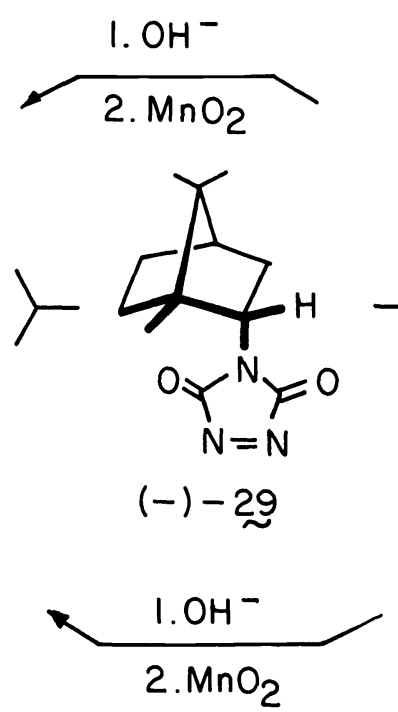

2. $\mathrm{MnO}_{2}$
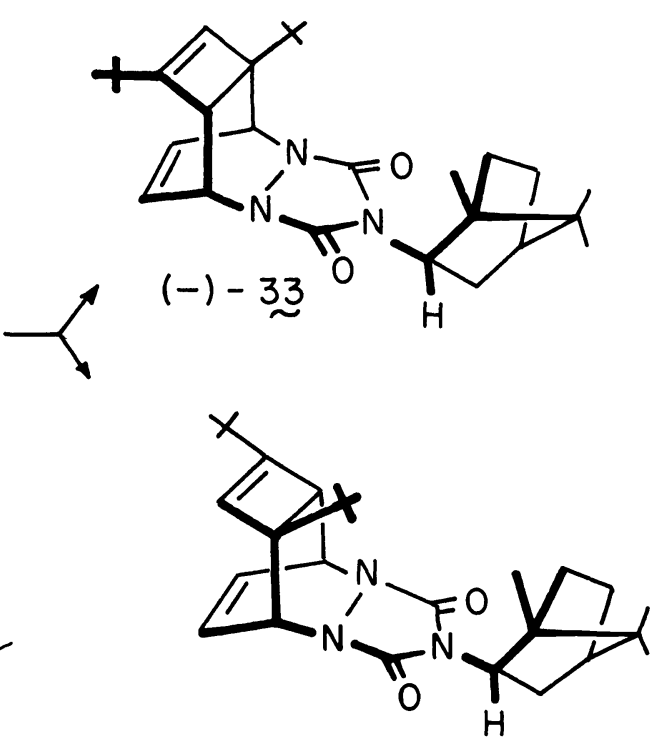

$(+)-34$

\section{INCREASE IN SYNTHETIC LATITUDE: CARBONYL AND $\alpha$-DICARBONYL PHOTOEXTRUSION} ROUTES

The direct resolvability of racemic cyclooctatetraenes has, in turn, provided unlimited latitude in developing convenient synthetic approaches to chiral [8]annulenes. In this connection, protocols involving ultimate photochemical decarbonylation of bridged ketones and $\alpha$-diketones are particularly noteworthy. For example, warrener and his coworkers have shown that controlled irradiation of ketones 35 and 36 , available by Diels-Alder cycloaddition of cis-3,4-dichlorocyclobutene to 2,5-dimethyl-3,4-diphenylcyclopentadienone followed by dechlorination with zinc dust, leads to the rather stable bicyclo[4.2.0] 0 ctatriene 37 (Scheme V). ${ }^{24}$ Heating of 37 at $60-80^{\circ} \mathrm{C}$ for several hours provides cyclooctatetraene 38 which, not surprisingly, prefers to exist in equilibrium with 39.

1,3- and 1,4-disubstituted COT's have been prepared via related chemistry which utilizes O-benzoquinones as starting materials. Condensation of these substrates with cyclobutadiene provides bright yellow crystalline adducts of type 40 and 42 . When irradiated at $0-5^{\circ} \mathrm{C}$, these $\alpha$-diketones evolve carbon monoxide and form the bicyclo[4.2.0]octatrienes 41 and 43 , respectively (Scheme VI).23,25

A unique feature of the approaches outlined in Schemes V and VI is the initial formation of bicyclic valence tautomers. Bicyclo[4.2.0]octatrienes 37,41 , and 43 have proven to be more stable than the parent hydrocarbon of the series. The heightened activation energies (Table 1) appear to have their origin chiefly in those steric considerations which come into play in the transition states associated with disrotatory cleavage of the central bond.

\section{RACEMIZATION AND ITS RELATIONSHIP TO ISODYNAMICAL BEHAVIOR}

The kinetic intricacies associated with ring inversion and bond shifting within an optically active cyclooctatetraene such as the 1,2,3-trimethyl derivative 46 are outlined in Scheme VII. Four isodynamical structures are required to completely define the mutual interconversion profile. Simple mechanical ring inversion serves to convert (-)-A to $(+)-\underline{C}$ or $(+)-B$ to $(-)-D$ at a rate which shall be defined as $k_{1}$. When energy adequate to

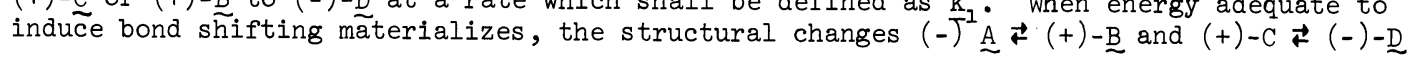


SCHEME<smiles>CC12C(=O)C(C)(C(c3ccccc3)=C1c1ccccc1)[C@H]1C=C[C@H]2C1</smiles>

35

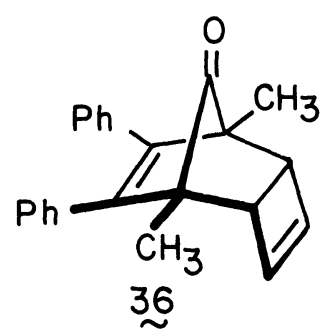<smiles>C[14CH2]</smiles>

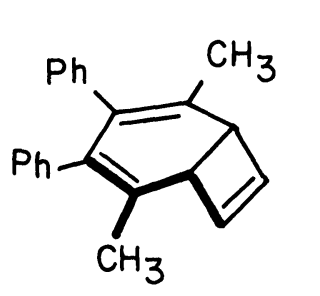

37

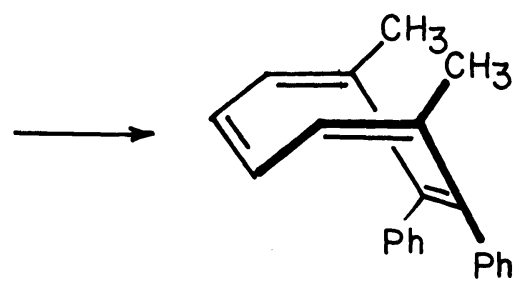

38

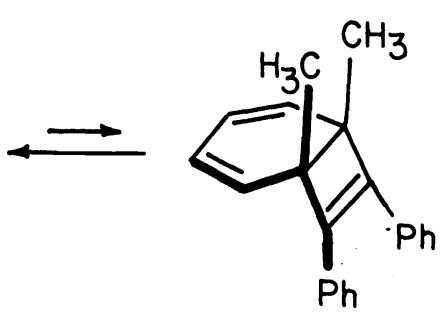

39

SCHEME 开

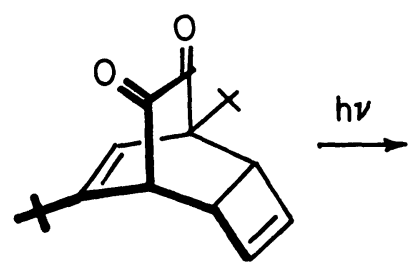

40

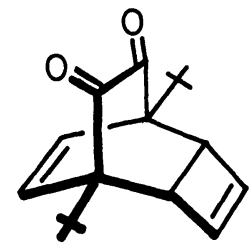

42

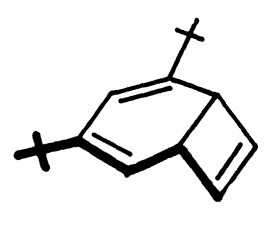

$\stackrel{41}{\sim}$
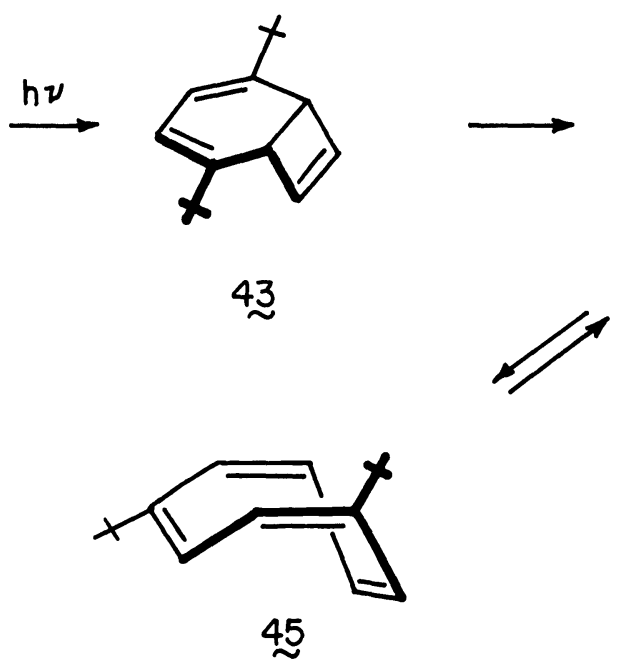

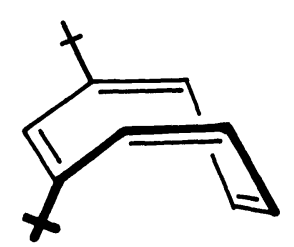

32

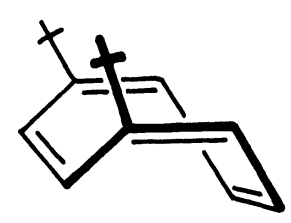

44 
Table I. Kinetices of Electrocyclic Behavior of Selected Bicyclooctatrienes

\begin{tabular}{|c|c|c|c|}
\hline compd & $\underset{\mathrm{k}_{\mathrm{cal}} / \mathrm{mol}}{\mathrm{E}_{\mathrm{act}}}$ & $\begin{array}{l}\Delta \mathrm{G}\left(25^{\circ} \mathrm{C}\right) \\
\mathrm{kcal} / \mathrm{mol}\end{array}$ & Ref. \\
\hline & 18.7 & - & 26 \\
\hline & 28.4 & 23.2 & 23 \\
\hline 43 & 31.1 & 32.9 & 25 \\
\hline 39 & 22.2 & 19.7 & 27 \\
\hline & 23.7 & 21.1 & 27 \\
\hline & \multicolumn{2}{|c|}{$\begin{array}{l}\text { no detectable ring opening; } \\
\text { thermodynamically favored }\end{array}$} & 28 \\
\hline
\end{tabular}

occur, again with loss of optical activity. The rate of these processes is defined as $k_{2}$. If the transition state for $B S$ is indeed planar and delocalized, then allowance must $b e^{-2}$ made for the incursion of ring inversion with bond shifting. This assumption necessitates

\section{SCHEME VIII}

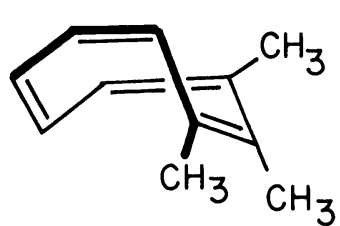

$$
\begin{aligned}
& (-)-\stackrel{A}{\sim} \\
& \underline{k}_{2} \|
\end{aligned}
$$

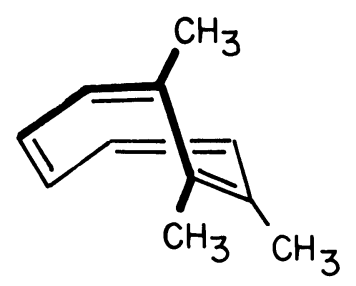

$(+)-\stackrel{B}{\sim}$
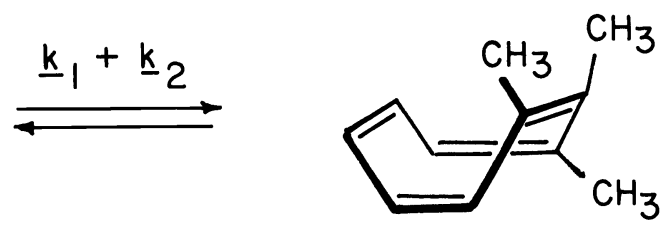

$(+)-\underset{c}{ }$<smiles>[R][C]=C</smiles>

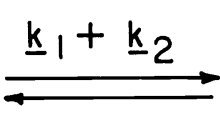

$$
(-)-D
$$


that due kinetic consideration be given the changes $(-)-\underset{\sim}{A} \vec{t}(-)-\underline{D}$ and $(+)-\underline{\underline{B}} \vec{t}(+)-\underset{\sim}{C}$. The latter inclusion allows for the possibility that the species present at the BS transition state possesses equal opportunity for passage to any of the three isodynamical forms as well as return to starting material.

Accordingly, the overall rate at which optical activity is lost can be defined as in eq 1 : $-\mathrm{d} \alpha / \mathrm{dt}=2\left(\underline{k}_{1}+2 \underline{k}_{2}\right) \alpha$

Integration between the limits of $t=0$ and $\underline{t}=\mathrm{t}$ yields the integrated rate law

$-\ln \alpha=2^{-}\left(\underline{k}_{1}+2 \underline{k}_{2}\right) \underline{t}-\ln \alpha_{0}$

The factor 2 is seen to be obligatory because enantiomer production not only causes loss of the molecule undergoing dynamic change, but also negates the rotatory power of a second.

In COT's such as 32 and 46 , both bond shift isomers are chiral and therefore individually capable of supporting optical activity. The situation involving isomer pairs such as 15 and 18 or 38 and 47 (Scheme VIII) ${ }^{27}$ is not trivially different. Because 15 and 38 are meso

\section{SCHEME 픔}
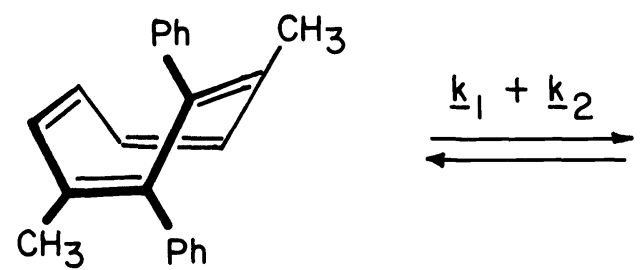

$$
(-)-47
$$<smiles>[Y6][14CH2][14CH2]</smiles><smiles></smiles>

$( \pm)-38$

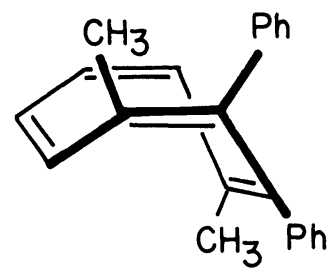

$$
(+)-47
$$
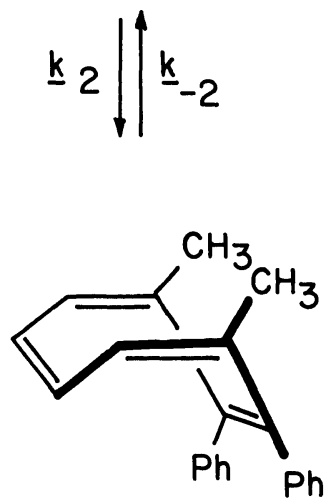

$( \pm)-38$

compounds, the rate at which they transform into their bond shift isomers need not be identical to $\mathrm{k}$ and is therefore designated as $\mathrm{k}_{-} \mathrm{j}^{\cdot}$ Comparable kinetic analysis indicates that the rate at which 18 and 36 lose optical activity is given by the expression

$$
-\ln \alpha=\widetilde{2}\left(2 k_{2}+\underline{k}_{1}\right) \underline{t}-\ln \alpha_{0}
$$

Here, the factor 2 is again obligatory, but for two quite unrelated reasons. As in the case of $\underline{C}_{2}$-symmetric COT's, production of the enantiomer leads to a twofold enhancement in the decrease of $\alpha$. When the meso compound is produced, racemization also results but additional rotatory power is not lost. However, 38 is generated twice as rapidly as enantiomer 47 (Scheme VI).

The preceding treatment reveals that any rate constant for racemization of an optically active COT is a composite of $\underline{k}_{1}$ and $k_{2}$. Therefore, it becomes necessary to carry out an independent determination of the rate of RI or BS in order to achieve complete numerical definition of the relevant dynamic parameters.

\section{INDEPFNDFNT MEASURFMENT OF BOND SHIFTING RATSS}

In order to extract values for $\mathrm{k}$, the rate constants for $\mathrm{RI}$, from the composite racemization kinetic expressions (eq $\bar{s} 2$ and 3 ), rate constants were measured in the same temperature range. Varied techniques for quantifying this phenomenon $r \in q u i r e d$ development. When the equilibrium in question involves [8]annulene bond shift isomer pairs which are $\mathrm{C}_{\mathrm{s}}$ and $\mathrm{C}_{2}$ symmetric, e.g., $15 \rightleftarrows 18$ and $38 \overrightarrow{47}$, certain chemical shifts of the two isomers are sufficiently distinctive to provide for $\widetilde{d i r e c t}^{1} \mathrm{H}$ NMR measurement of $\underline{\mathrm{k}}_{2}$ and $\underline{\mathrm{k}}-2^{\cdot}$. In 
practice, degassed diglyme- $\underline{d}_{14}$ solutions of the COT ( $70 \%$ or more isomerically enriched) need only be heated and specific signal intensities (usually methyl absorptions) integrated relative to an internal standard as a function of time.

When the bond shift isomers are not constituted of $\mathrm{dl}$ and meso forms as above, the acquisition of bond shifting kinetic data becomes more challenging. In the particular case of 1,2,3-trimethylCOT (46), advantage was taken of the observation that its room temperature $60-\mathrm{MHz}{ }^{1} \mathrm{H}$ NMR spectrum (in $\mathrm{CDCl}_{3}$ ) consists of three well separated methyl singlets. Accordingly, our earlier synthetic approach was modified to allow for incorporation of two vicinal $-\mathrm{CD}_{3}$ groups (Scheme IX). ${ }^{29}$ Bromination-dehydrobromination of

\section{SCHEME IX}<smiles>CC12CC=CCC1C[S+](=O)(=O)C2</smiles><smiles>[R][13CH][13CH][13CH3]</smiles>

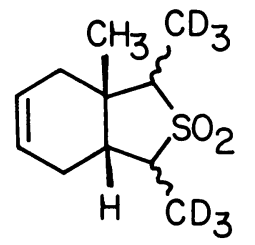<smiles>[Al][Ba][Ba]</smiles><smiles>[Mg][Mg]</smiles><smiles>CC12C=CC=CC1C(C(=O)O)=C(C(=O)[O-])C2</smiles>

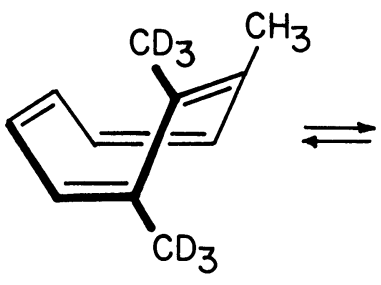

50

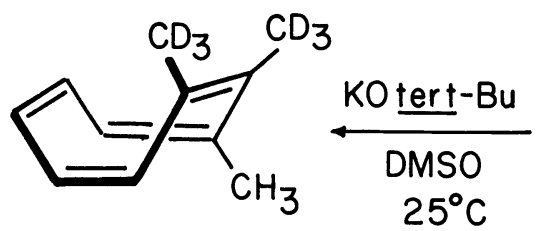

49

bicyclooctadiene 48 delivered a $4: 1$ mixture of 49 and 50. Since planimetric integration of the methyl signals individually characteristic of 49 and 50 provides quantities that are proportional to the concentration of each isomer present, the rates at which equilibrium is reached were easily determined at various temperatures. In treating kinetic data obtained in this fashion, it becomes necessary to make correction for steric deuterium isotope effects because of the smaller vibrational amplitudes of C-D relative to C-H bonds. For the present purposes, a fractionation factor $\left(\underline{k}_{H} / \underline{k}_{D}\right)$ of 0.83 was adopted, ${ }^{29}$ largely on the basis of precedent. ${ }^{30}$

The tert-butyl singlets of 32 have identical chemical shifts. Consequently, the independent determination of $\mathrm{k}_{2}$ in this system has to be carried out in a different manner. As H-D exchange in cyclobutadieneiron tricarbonyl can be effected in $\mathrm{CF}_{3} \mathrm{COOD}$ solution, ${ }^{31}$ the preparation of 21 (Scheme $\mathrm{X}$ ) could be accomplished without complication. The photolysis of 51 at $0^{\circ} \mathrm{C}$ in chloroform solution afforded uniquely 52 whose deuterium substitution plan was confirmed by spectral analysis and conversion to its $\mathbb{N}$-phenyltriazolinedione adduct. In particular, the ${ }^{1} \mathrm{H}$ NMR spectrum of 52 is characterized by two relatively narrow vinyl proton multiplets centered at 85.7 and 5.23 . As the ring opening of 52 is allowed to proceed, a gradual diminution in the intensity of the 85.23 signal is seen. Simultaneously, a very downfield peak at 85.96 increases more rapidly in area than another at 5.43. To our ultimate advantage, the ring protons positioned between the tert-butyl groups in 52-54 resonate at the same chemical shift (5.7). On the assumption that electrocyclization within 52 is also governed by the strictures of orbital symmetry, 53 will form first and be the species responsible for the 5.96 absorption. The ensuing reversible bond shifting which interlinks 53 and 54 provides the ultimate means for equilibrating the entire system.

Again, $\underline{k}_{2}$ and $\underline{k}_{-2}$ are interrelated by a deuterium isotope effect. However, in this instance the issue revolves around the degree of kinetic deceleration which materializes when one of the tert-butyl groups passes by a neighboring C-H (relative to a shorter C-D) bond with which it is not already coplanar. This effect has been deemed to be adequately small to allow $\underline{\mathrm{k}}_{2}$ to be set equal to $\underline{\mathrm{k}}_{-}$.

Exemplary bond shifting kinetic data, together with activation parameters, appear in Table II. 


\section{SCHEME $\mathbb{X}$}

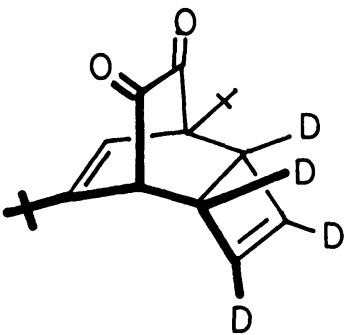

5

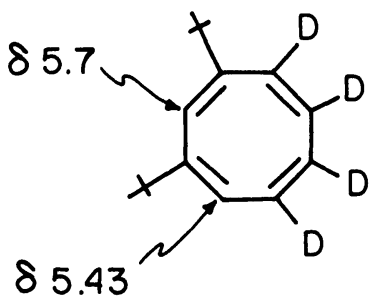

54

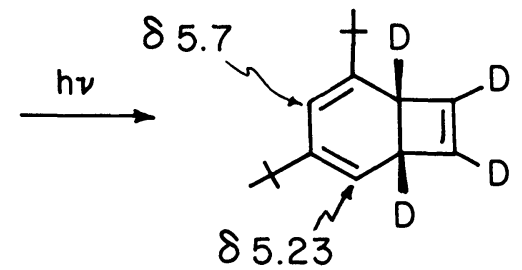

52

$\Delta$

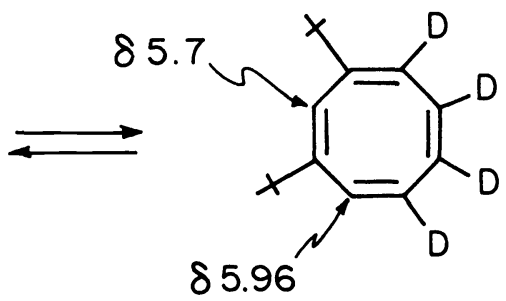

53

$\underset{\sim \sim \sim}{\text { Table }} \underset{\sim \sim}{\text { II. }}$ Bond Shifting for Sterically Congested Cyclooctatetraenes

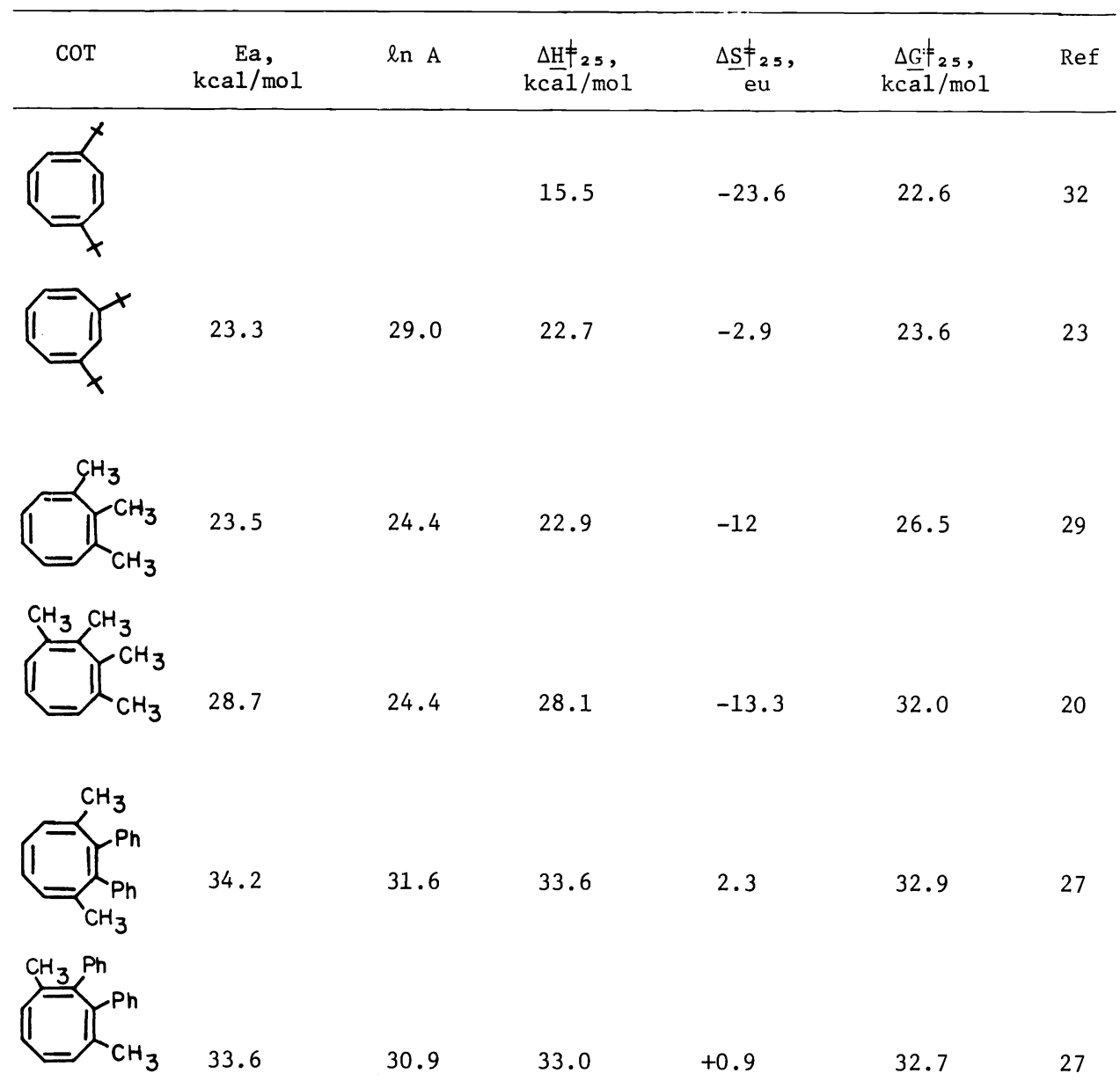




\section{RING INVERSION ENERGFTICS}

Since all of the chiral COT's listed in Table II are capable of isolation in optically active form, the magnitudes of the barriers to their ring inversion can be perceived a priori to be adequately high to deter attainment of a planar conformation. Simple computations based upon eqs 2 and 3 , racemization kinetic data, and bond shifting rate constants have provided the ring inversion barriers summarized in Table III.

Table III. Ring Inversion Barriers for Chiral Cyclooctatetraenes

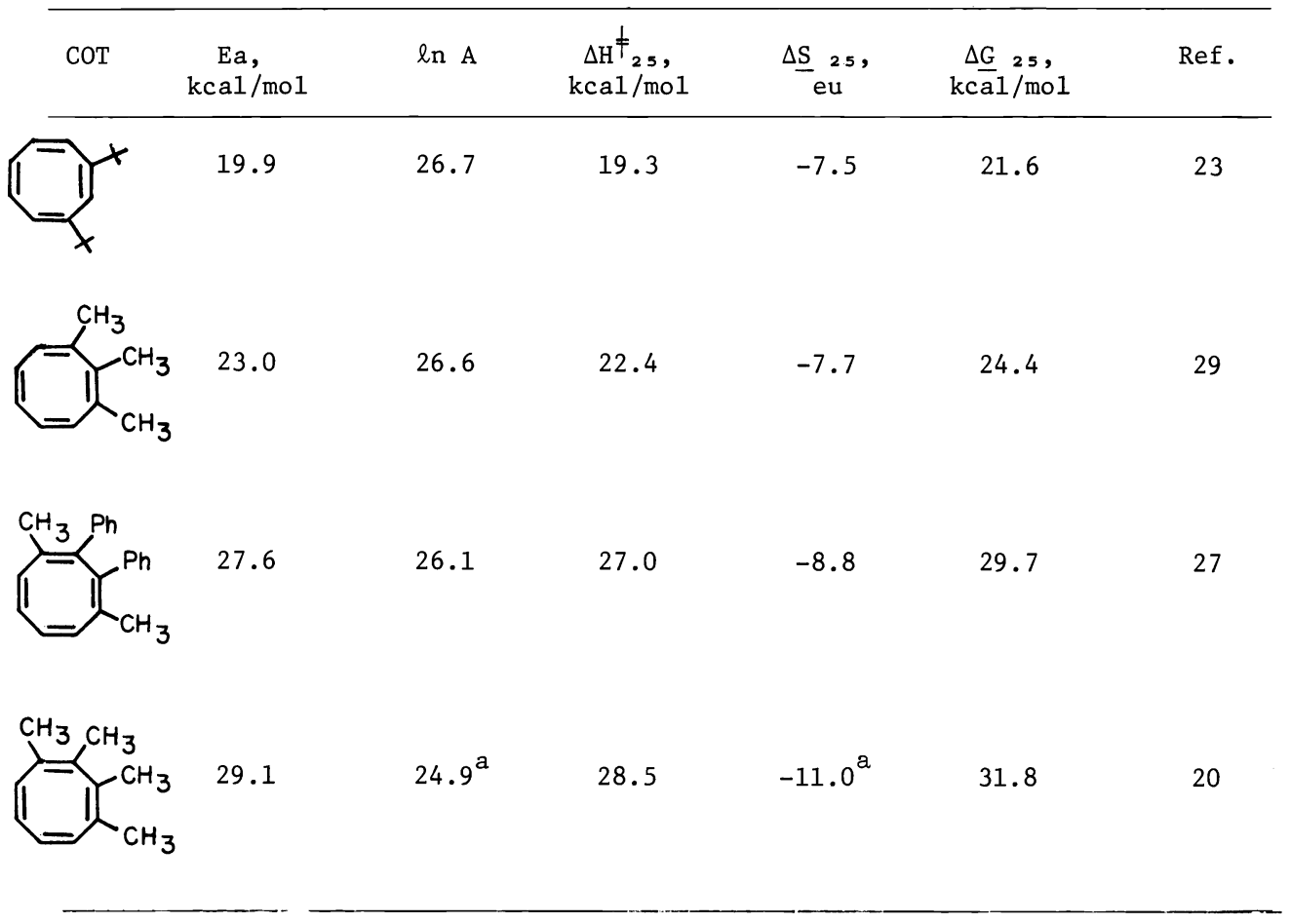

a The original report lacked a minus sign for the $\Delta \underline{S}^{\ddagger}$ value and had a typographical error in the $\ln$ A value.

At this point, it becomes informative to recognize the results of calculations due chiefly to Allinger, ${ }^{12}$ Dewar, ${ }^{33}$ and Wipf $^{34}$ which deal with mechanical inversion in substituted СОT. Their studies reveal that attainment of planar alternate geometry (cf 2 ) is disfavored predominantly by increases in van der Waals and angular bending energies. To be sure, a decrease in torsional energy also accompanies this conformational change, but this effect is of lesser importance. A total energy increase of $15.1 \mathrm{kcal} / \mathrm{mol}$ has been estimated for flattening the [8]annulene framework into the optimized $D_{\text {in }}$ planar geometry. The important question which now arises is to what degree the angle bending and van der Waals forces which tend to pucker the eight-membered ring are counterbalanced by any $\pi$-electron delocalization which may be striving to flatten the system. It must first be emphasized that the above facts do not mean that transition states such as $\precsim$ are electronically destabilized relative to an open-chain polyene with the same number and types of bonds. In actuality, this comparison is not possible because cyclooctatetraenes do not have an option to be acyclic; rather, the only available choices are to be cyclic, and flat or puckered in some fashion. ${ }^{35}$ Significantly, all parties agree that planarity within COT is energetically advantageous insofar as its $\pi$ component is concerned. Therefore, as pointed out elsewhere in another context, ${ }^{36}$ any equation of the concept of "antiaromaticity" with a tendency for nonplanarity generates an erroneous impression of the prevailing energetics and has been a 
source of confusion in the past.

\section{CONSEQUFNCES OF HIGH PERIPHERAL STERIC CONGESTION}

An early variable temperature ${ }^{1} \mathrm{H}$ NMR examination by Meisinger ${ }^{37}$ of 1,2-dimethylCOT showed that this hydrocarbon displays at $40^{\circ} \mathrm{C}$ two sharp singlets at 81.68 and 1.82 of unequal weighting (the downfield signal is the more intense). At $94^{\circ} \mathrm{C}$, appreciable broadening of

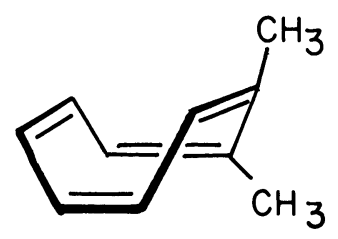
55

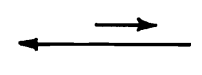

\section{3}

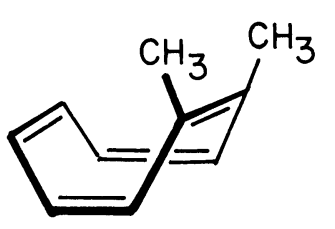

56

the two peaks is evident and at $122^{\circ} \mathrm{C}$ coalescence occurs with the appearance of a sharp singlet at 81.75 . This reversible behavior has been attributed to a thermodynamic preference for 55 where methyl-methyl interactions are lessened because of their location on neighboring double bonds. The $\underline{C}_{2}$ symmetry of 55 leads to identity of its methyl groups and the appearance of the sharp singlet at 1.82 . Bond shift isomer 56 is already accessible at ambient temperature as indicated by the singlet at 1.68 , but its concentration lags behind that of 55 until temperatures in excess of $100^{\circ} \mathrm{C}$ are reached. Since 56 is of $\underline{\mathrm{C}_{\mathbf{s}}}$ symmetry, there is no entropy of mixing and the equilibrium is enthalpy controlled.

Whereas $\Delta \mathrm{G}^{ \pm} \mathrm{BS}\left(122^{\circ} \mathrm{C}\right)$ for 56 has been determined to be $21.1 \mathrm{kcal} / \mathrm{mol},{ }^{37}$ rates and activation parameters for ring inversion in 55 are unavailable. However, extrapolation of the preceding data and that obtained by Anet and Bock for 8-methylcyclooctatetraenylmethyl 0 -methylmandelate ${ }^{8}$ leads to an approximate $\Delta G^{ \pm} \mathrm{RI}\left(122^{\circ} \mathrm{C}\right)$ of $18.4 \mathrm{kcal} / \mathrm{mol}$. The 1,2,3trimethyl $\left(\Delta \underline{G}^{ \pm} R I\left(122^{\circ} \mathrm{C}\right)=25.5 \mathrm{kcal} / \mathrm{mol}\right)$ and $1,2,3,4$-tetramethyl $\left(\Delta \underline{G}^{ \pm} \mathrm{RI}=32.9 \mathrm{kcal} / \mathrm{mol}\right)$ substitution plans further impede ring inversion and to substantial degrees $\left(\Delta \Delta G^{ \pm}=7.1\right.$ and $14.5 \mathrm{kcal} / \mathrm{mol}$, respectively). As reflected in Figure 1, a particularly striking feature

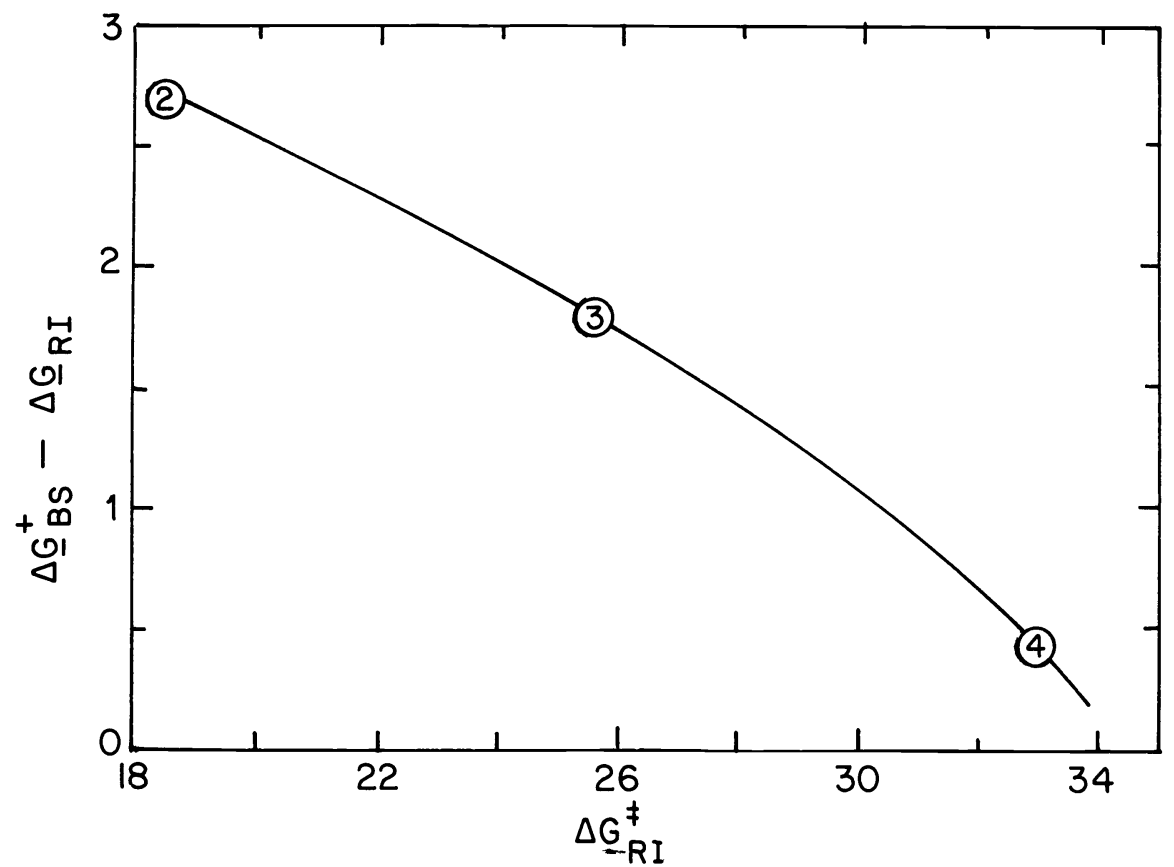

Figure 1. Plot of $\Delta \mathrm{G}^{\ddagger} \mathrm{BS}\left(122^{\circ} \mathrm{C}\right)-\Delta \mathrm{G}^{\ddagger} \mathrm{RT}\left(122^{\circ} \mathrm{C}\right)$ vs $\Delta \mathrm{G}^{\ddagger} \mathrm{RI}\left(122^{\circ} \mathrm{C}\right)$ as a function of the level of alkyl substitution. The encircled number relates to the number of peripheral methyl groups. 
of these data is the rather large incremental impedance to ring flattening which the fourth methyl group introduces.

The differences in free energies of activation realized above have been treated as the standard values for steric strain due to intramolecular crowding in the planar alternate [8]annulene structure 57. Viewed in this way, the degree of added strain which develops

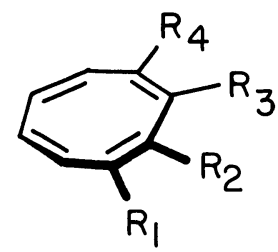

$$
\begin{gathered}
\underset{2}{2 a}, R_{1}=R_{4}=H ; R_{2}=R_{3}=C H_{3} \\
\underset{\sim}{b}, R_{1}=H ; R_{2}=R_{3}=R_{4}=C H_{3} \\
\underset{\sim}{c} R_{1}=R_{2}=R_{3}=R_{4}=C_{3}
\end{gathered}
$$

in the transition state attained during flattening of the 1,2-dimethyl derivative can be considered to arise in large part because of the $\mathrm{CH}_{3} / \mathrm{CH}_{3}$ interaction. Third and fourth methyl groups introduce added strain, including Me-Me buttressing effects not present in 57a. In the 1,2,3-trimethyl example, a second Me-Me interaction across a $\mathrm{C}=\mathrm{C}$ bond is added. Further, the central methyl group is now positioned between the two other methyls. Additional steric impedance is therefore introduced in the form of methyl buttressing effects (MBF's).

Equation 4, which has been developed to allow for estimation of MBE contributions in 46 and $18,{ }^{35}$ generates values of 3.1 and $3.4 \mathrm{kcal} / \mathrm{mol}$, respectively. These data prove to

$$
\Delta \Delta \underline{G}^{ \pm}=\Delta \Delta \mathrm{Me}-\mathrm{Me}(-)+\Delta \Delta \underline{G}_{\mathrm{Me}-\mathrm{Me}}(=)+\Delta \mathrm{G}_{\mathrm{MBE}}
$$

be consistent with MBE values obtained in unrelated studies. ${ }^{38}$ Solution of the same expression for octamethylCOT (using Allinger's computed barrier to ring inversion of 93.7 $\mathrm{kcal} / \mathrm{mol}^{12}$ ) generates a value of $5.6 \mathrm{kcal} / \mathrm{mol}$. This finding is as expected, since $\Delta G_{M B E}$ is not a real constant but should increase with increasing congestion.

Two important points emerge from the preceding discussion and analysis. Because the $\Delta \Delta \underline{G}^{ \pm}$ differences decrease as the quantities themselves increase, incremental substitution of the [8]annulene framework to relatively high levels is clearly seen to becloud the energetics attending flattening of the [8]annulene core. Accordingly, to the extent that the contribution of electronic factors to $\Delta \Delta \underline{G}^{ \pm}$wish to be maximized, then greater insight will be gained as the number of pendant groups is reduced. On the other hand, if the intention is to investigate steric interactions about the periphery of planar eight-membered rings (both localized and delocalized), then steric crowding becomes relevant. Importantly, the present methodology allows for detailed probing of either phenomenon, as seen below.

\section{DYNAMIC BEHAVIOR OF THE 1,3-DI-TERT-BUTYL DERIVATIVF:}

The steadily increasing barriers to BS and RI which materialize upon incremental vicinal methyl substitution of the COT framework can without any doubt be ascribed to the existence of greater repulsive interactions in the transition states relative to the ground states. If either activated complex were highly puckered or of crown geometry, the reverse ordering would be expected. Identical reasoning rules out bicyclo[3.3.0]octanediyl intermediates. ${ }^{39^{\circ}}$ As with the entropies of activation for ring inversion (Table III), the negative $\Delta \underline{S}^{ \pm} B S$ values (Table II) are likewise in agreement with flattening of the ring.

The $\Delta G^{ \pm}\left(25^{\circ} \mathrm{C}\right)$ for ring inversion in the 1,3-di-tert-butyl derivative $32(21.6 \mathrm{kcal} / \mathrm{mol})$ indicates that its potential functions for torsional strain and bond angle deformation exceed those of various monosubstituted derivatives $\left[\Delta G^{ \pm}\left(-25\right.\right.$ to $\left.\left.0^{\circ} \mathrm{C}\right)=12.7-14.7 \mathrm{kcal} / \mathrm{mol}\right], 7,8$ but fall below those of the tri- and tetramethyl congeners. A total energy increase of $15.1 \mathrm{kcal} / \mathrm{mol}$ has been computed as the enerey cost for flattening the unsubstituted COT ring into an optimized $\mathrm{D}$ planar geometry. ${ }^{12}$ The principal factors associated with this conformational change are expansion of the internal bond angles from $124^{\circ}$ to $135^{\circ}$, enhanced steric compression of the pairs of hydrogens attached to the same double bond, and a buttressing effect of all the hydrogens on their neighbors. For 32, the enhanced level of nonbonded steric interaction involving the noncontiguous tert-but $\widetilde{\mathrm{l}}$ groups on $\mathrm{C}-\mathrm{I}$ and $\mathrm{C}-3$ and the flanking ring hydrogen atoms in the transition state is the main cause of the increase in the energy barrier. In the tub conformation of 32 , the tert-butyl substituents 
are freely rotating $\left({ }^{1} \mathrm{H}\right.$ NMR analysis). Such motions appear substantively more restricted in planar alternate transition state 58 , as reflected in the rather negative $\Delta S^{ \pm}\left(25^{\circ} \mathrm{C}\right)$ term $(-7.5 \mathrm{eu})$. In composite terms, the kinetic data obtained in our studies are most

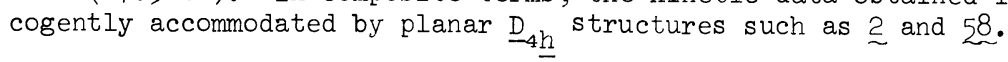

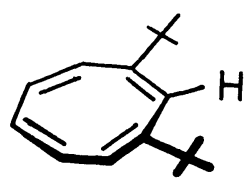

58

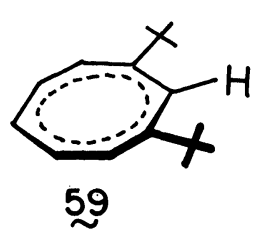

59

As commonly observed, the barrier to bond shifting in 32 lies above that due to ring inversion. In actuality, the ca $6.5 \mathrm{kcal} / \mathrm{mol}$ of added RI destabilization energy associated with 58 should be transferable within narrow limits to the transition state for bond shifting (59) if both structures share the common feature of [8] annulene planarity. The Jahn-Teller theorem ${ }^{4 O}$ states that 59 and related structures could well be geometrically unstable with respect to some displacement of atoms which removes any $\pi$-orbital degeneracy which may exist. A key question is whether any distortions that would buckle the ring or make the $\mathrm{C}-\mathrm{C}$ bonds alternately longer or shorter would allow for bond shift isomer interconversion. As is usual in such circumstances, direct evidence relating to this question is not available. However, it is clear that if bond alternation were to arise, the accentuation of this effect could not be so great as to compare to 58 .

At the present time, we believe that the weight of evidence has become sufficient to justify acceptance of 58 and 59 as accurate descriptors of the RI and BS transition states associated with cyclooctatetraene automerization, at least in those situations where excessive peripheral strain is not an issue. Thus, to the extent that the delocalization energy associated with 59 can be approximated by the relationship given in eq 5

$$
\widetilde{E}_{D}=\Delta H^{ \pm} R I-\Delta H^{ \pm} B S
$$

delocalization of the $8 \pi$ electrons is seen to be destabilizing by $3.4 \mathrm{kcal} / \mathrm{mol}$. In 1965 , Dewar and Gleicher described PPP and SPO molecular orbital calculations which led them to conclude that $E_{R}$ within a $D_{8 h}$ perimeter should be antiaromatic by $4 \mathrm{kcal} / \mathrm{mol} .{ }^{41}$ The correspondence between theoretical and experimental values is remarkably close.

\section{PROBE OF THE METHYL/PHENYL DICHOTOMY IN TETRASUBSTITUTED CYCLOOCTATETRAENES}

The possibility remains that for severely crowded COT's, peripheral substituents may move through the developing plane of the ring carbons at different times in order to avoid excessive congestion. The RI and BS transition states can be expected to be differently responsive to such external influences because of dissimilar intraannular bond lengths, levels of $\pi$-electron delocalization, and the like. Using the techniques described above, the magnitudes of $\Delta \Delta G^{ \pm}$which separate $k_{B S}$ and $k_{R I}$ in any cyclooctatetraene are determined by subtraction of two relatively small and rather accurate numbers. Because of the high reliability of the kinetic data, it has proven possible to uncover a dichotomy in transition state behavior in the case of the dimethyldiphenylCOT's 38 and 47 .

The severe crowding which is possible within the tetramethyl derivatives 15 and 18 was previously recognized to cause $\Delta G^{ \pm}\left(25^{\circ} \mathrm{C}\right.$ ) for BS and RI to become equal ( $\left.30^{\circ} .9 \mathrm{kcaItmol}\right)$. This proved to be the first example where an energetic imbalance favoring ring inversion has not prevailed. With replacement of the pair of internal methyl groups by phenyl as in 60 and 61 , it becomes possible to assess the level of steric strain due to intramolecular crowding in 60. Furthermore, since the bond shifting pathway which interconnects 60 and 61 should

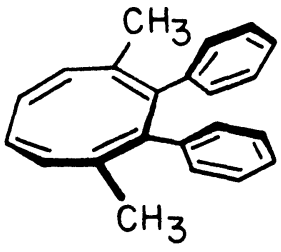

60

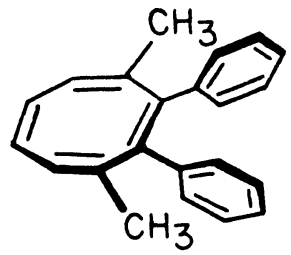

$\underset{\sim}{61}$

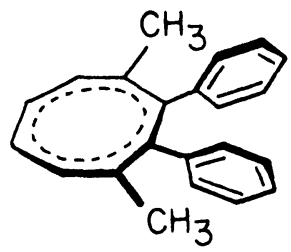

62 
be mediated by 62 , an analysis of the differences or similarities in steric interaction at the respective transition states is made possible and provides an independent probe of the relative size of methyl versus phenyl in activated complexes of this type.

In 60 , the aryl groups appear (on the basis of molecular models) to experience crowding adequately severe to impose a high barrier to rotation of any magnitude. In-plane splaying involving bending of the phenyl-COT sigma bonds as in 63 cannot occur to any appreciable extent because of the buttressing effects of the flanking methyl groups. Therefore, a widening of $\theta$ by this mechanism cannot materialize without a concomitant increase in crowding between phenyl and methyl substituents. Out-of-plane splaying as in 64 would

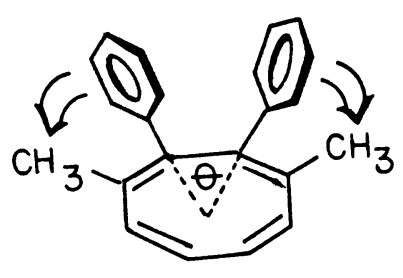

63

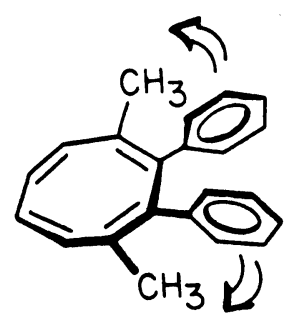

64

involve displacement of the phenyl rings (and to a lesser extent the COT ring atoms $\mathrm{C}_{2}$ and $\mathrm{C}_{3}$ ) to opposite sides of the plane defined by the right-membered ring. This description is equivalent to the assumption that the aryl groups do not pass simultaneously through the plane defined by the [8]annulene core. Additionally, there exists no reason to discount the possibility that the nondelocalized COT nucleus can effectively absorb a portion of the overall strain energy and efficiently distribute it throughout its framework by suitable angle bending, bond stretching and compression (but short of $\pi$-electron delocalization), and in- and out-of-plane nuclear displacements.

Inspection of Tables II and III reveals that the activation energy for ring inversion in 47 $(27.6 \mathrm{kcal} / \mathrm{mol})$ is higher than that of $1,2,3$-trimethylCOT $(23.0 \mathrm{kcal} / \mathrm{mol})$, but appreciabl lower than that of $1,2,3,4$-tetramethylCOT $(29.1 \mathrm{kcal} / \mathrm{mol})$. This ordering is opposite to that encountered with bond shifting. It appears, therefore, that the pair of phenyl groups in 60 cause the excessive steric crowding to be spread throughout the [8]annulene framework, perhaps in the form of greater ring buckling. The implication is, of course, that phenyl groups located in the bisector plane of a flatten polyunsaturated eight-membered ring have greater steric requirements than comparably situated methyl groups during ring inversion.

During the course of $\pi$ bond shifting within 47 , the involvement of 62 is presumed. Generally speaking, the level of antiaromaticity within such $4 \mathrm{n} \pi$-e lectron rings is sufficiently low that the $\pi$ network should actually prefer to be planar and delocalized. Arrival at a planar structure with equal bond lengths as in 62 serves to restrict those conformational degrees of freedom previously available to the medium ring in 60 where cyclic conjugation is absent. A likely reason why 62 is more difficult to attain than its tetramethyl counterpart is the enhanced in-plane congestion of the four peripheral substituents unavoidably caused by the greater need for planarity within the delocalized [8]annulene. The difference of approximately $6 \mathrm{kcal} / \mathrm{mol}$ in the Eact's for BS and RI in 47 is due in part to the heightened compressional influences and in part to the energy required to drive the delocalization. Since an unfavorable resonance energy of $2-4 \mathrm{kcal} / \mathrm{mol}$ is generally seen, the phenyl groups in 62 appear to be exerting relatively normal (i.e. phenyl $>$ methyl) steric perturbations. Thus, an interesting topological distinction between 60 and 62 appears to exist.

\section{ANTIAROMATIC NATURE OF PLANAR DELOCALIZED [8]ANNULENES}

The implications of the results discussed above should now be made clear. Of the forces operating in progressing from a ground-state tub conformation to a planar delocalized transition state, angle strain, van der Waals repulsions, and related phenomena contribute ca $85 \%$ of the enthalpy demands. The remaining $15 \%$ can be traced to resonance destabilization. Consequently, the cause of COT nonplanarity has minimal to do with the energetics of antiaromatic conjugation. This is not to say that COT is not antiaromatic, for the [8]annulene ring system is unquestionably so. However, the antiaromaticity level is weak and incapable of dominating the overall conformation energetics. Most importantly, one must not necessarily equate the concept of antiaromaticity with the tendency to be nonplanar. In the case of a molecule that is very antiaromatic, the system would rather be nonplanar because the antiaromaticity overwhelms the tendency for planarity. As concerns 
cyclooctatetraenes, the level of antiaromaticity is sufficiently low that the $\pi$ network would prefer to be planar and delocalized. In actuality, the relative magnitude of the antiaromaticity is so much less than the energy required to twist about the single bonds that the eight-membered rings are forced to be puckered.

What is the causative factor underlying the low antiaromaticity level of a planar delocalized [8]annulene? As can be seen from the correlation diagram illustrated in Figure 2 , an orbital crossing is required to achieve the interconversion of bond shift isomers. The interconversion is therefore forbidden. Two of the three possible singlet configurations of $D_{0}$ COT possess the same energy and thus repel each other stron:ly. This phenomenon might-well lead to a net lowering of the activation energy.
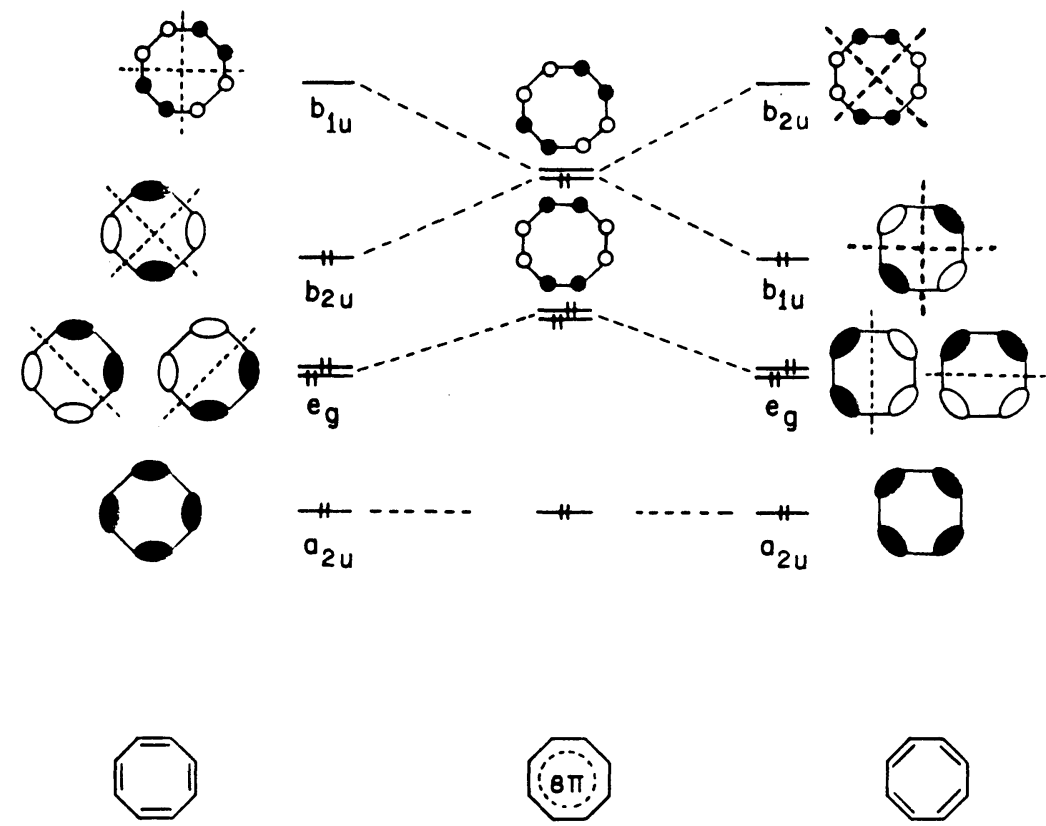<smiles>c1ccccc1</smiles>

$\mathrm{D}_{4 \mathrm{~h}}$

$D_{8 h}$

$\mathrm{D}_{4 \mathrm{~h}}$

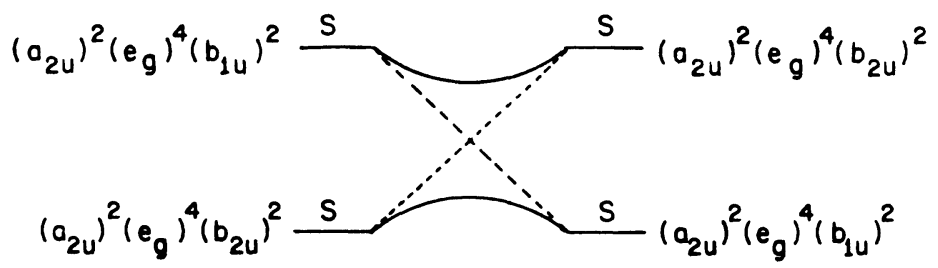

Figure 2. Correlation (top) and state diagrams (bottom) for bond shifting in $\operatorname{coT} .29$

\section{ACKNOWLEDGMENT}

Our research program in cyclooctatetraene chemistry has been and continues to be funded by the National Science Foundation.

\section{REFERENCES}

1. R: Willstätter and E. Waser, Dtsch. Chem. Gest. 44, 3423 (1911); R. Willstätter and M. Heidelberger, ibid. 46, 517 (1913). See also A.C. Cope and C.G. Overberger, J. Am. Chem. Soc. 69, 976 (1947); 70,1433 (1948).

2. E. Hückel, Z. Elektrochem. 43, 752 (1937). 
3. W. Reppe, O. Schlichting, K. Klager, and T. Toepel, Liebigs Ann. 560, I (1948).

4. G. Schröder, Cyclooctatetraen, Verlag Chemie, GmbH, Weinheim/Bergate. (1965); L.A. Paquette, Tetrahedron 31, 2855 (1975); G.I. Fray and R.G. Saxton, The Chemistry of Cyclooctatetraene and Its Derivatives, Cambridge University Press, New York (1978).

5. The smallest member of this series, cyclobutadiene, is planar: $\mathrm{T}$. Bally and $\mathrm{S}$. Masamune, Tetrahedron 36, 343 (1980).

6. W.B. Person, G.C. Pimentel, and K.S. Pitzer, J. Am. Chem. Soc. 74,3437 (1952); I.L. Karle, J. Chem. Phys. 20, 65 (1952); M. Traetteberg, Acta Chem. Scand. 20, 1724 (1966); G. Avitabile, P. Ganis, and V. Petracone, J. Phys. Chem. 73, 2378 (1969); J. Bordner, R.G. Parker, and R.H. Stanford, Jr., Acta Cryst. 28B, 1069 (1972); R.E. Cobbledick and F.W.B. Einstein, ibid. 33B, 2339 (1977).

7. J.F.M. Oth, Pure Appl. Chem. 25, 573 (1971).

8. F.A.L. Anet, J. Am. Chem. Soc. 84,671 (1962); F.A.L. Anet, A.J.R. Bourn, and Y.S. Lin, ibid. 86, 3576 (1964); F.A.L. Anet and L.A. Bock, ibid. 90,7130 (1968).

9. D.E. Gwynn, G.M. Whitesides, and J.D. Roberts, J. Am. Chem. Soc. 87, 2862 (1965).

10. J.F.M. Oth, R. Merenyi, T. Martini, and G. Schröder, Tetrahedron Lett. 3087 (1966).

11. P. Ganis, A. Musco, and P.A. Temussi, J. Phys. Chem. 73,3201 (1969).

13. N.I. Allinger, J.T. Sprague, and C.J. Finder, Tetrahedron 29, 2519 (1973). derivative possesses alternately short $(1.353 \AA)$ and long $(1.425 \AA)$ bonds: F.W.B. Einstein, A.C. Willis, W.R. Cullen, and R.L. Soulen, J. Chem. Soc. Chem. Commun. 526 (1981).

14. R. Huisgen, G. Mietzsch, G. Boche, and H. Seidl, Chem. Soc., Spec. Publ. 19, 3 (1965).

15. K. Mis low and H.D. Perlmutter, J. Am. Chem. Soc. 84,3591 (1962); G.H. Senkler, Jr., D. Gust, P.X. Riccobono, and K. Mislow, ibid. 94, 8626 (1972).

16. L.A. Paquette, J.M. Photis, K.B. Gifkins, and J. Clardy, J. Am. Chem. Soc. 27,3536 (1975); L.A. Paquette and J.M. Photis, Tetrahedron Lett. 1145 (1975); L.A. Paquette, J.M. Photis, and R. Micheli, J. Am. Chem. Soc. 99, 7899 (1977); L.A. Paquette, R.P. Micheli, and J.M. Photis, ibid. 22, 7911 (1977).

17. L.A. Paquette, J.M. Photis, and G.D. Ewing, J. Am. Chem. Soc. 97, 3538 (1975); L.A. Paquette and J.M. Photis, ibid. 28, 4936 (1976).

18. J.M. Photis and L.A. Paquette, J. Am. Chem. Soc. 96, 4715 (1974); Org. Synth. 27, $53(1977)$.

19. J.M. Gardlik, L.K. Johnson, L.A. Paquette, B.A. Solheim, J.P. Springer, and J. Clardy, J. Am. Chem. Soc. 101, 1615 (1979).

20. L.A. Paquette, J.M. Gardlik, L.K. Johnson, and K.J. McCullough, J. Am. Chem. Soc. 102, 5026 (1980).

21. J.M. Gardlik and L.A. Paquette, Tetrahedron Lett. 3597 (1979).

22. L.A. Paquette and R.F. Doehner, Jr., J. Org. Chem. 45, 5105 (1980); L.A. Paquette, R.F. Doehner, Jr., J.A. Jenkins, and J.F. Blount, J. Am. Chem. Soc. 102, 1188 (1980); J.A. Jenkins, R.E. Doehner, Jr., and L.A. Paquette, ibid. 102, 2131 (1980).

23. L.A. Paquette, Y. Hanzawa, K.J. McCullough, B. Tagle, $\bar{W}_{\cdot}^{-}$Swenson, and J. Clardy, J. Am. Chem. Soc. 103, 2262 (1981).

24. C.M. Anderson, I.W. McCay, and R.N. Warrener, Tetrahedron Lett. 2735 (1970); I.W. McCay and R.N. Warrener, ibid. 4779, 4783 (1970); R.N. Warrener, C.M. Anderson, I.W. McCay, and M.N. Paddon-Row, Austr. J. Chem. 30, 1481 (1977); R.N. Warrener, I.W. McCay, R.Y.S. Tan, and R.G. Russell, Tetrahe $\widetilde{d r o n}$ Lett. 3183 (1979).

25. Y. Hanzawa, G.J. Hefferon, and R. Samodral, unpublished results in this laboratory.

26. E. Vogel, H. Kiefer, and W.R. Roth, Angew. Chem., Int. Ed. Engl. 3, 442 (1964).

27. L.A. Paquette, Y. Hanzawa, G.J. Hefferon, and J.F. Blount, submitted for publication.

28. Y. Hanzawa and L.A. Paquette, J. Am. Chem. Soc. 103, 2269 (1981).

29. J.M. Gardlik, L.A. Paquette, and R. Gleiter, J. Am. Chem. Soc. 101, 1617 (1979); L.A. Paquette and J.M. Gardlik, ibid. 102, 5016 (1980).

30. L. Melander and R.E. Carter, Acta Chem. Scand. 18, 1138 (1964); R.E. Carter and L. Dahlgren, ibid. 23, 504 (1969); S.A. Sherrod and V. Boekelheide, J. Am. Chem. Soc. $24,5513(\overline{1972})$.

31. J.C. Barborak, Ph.D. Dissertation, University of Texas, 1968; L.A. Paquette, J.R. Malpass, and G.R. Krow, J. Am. Chem. Sos. 22, 1980 (1970).

32. M.H. Lyttle, A. Streitweiser, Jr., and R.Q. Kluttz, J. Am. Chem. Soc. 103, 3232 (1981).

33. M.J.S. Dewar, A. Harget, and E. Haselbach, J. Am. Chem. Soc. 21, 7521 (1969).

34. G. Wipff, U. Wahlgren, E. Kochanski, and J.M. Lehn, Chem. Phys. Lett. 11, 350 (1971).

35. L.A. Paquette and J.M. Gardlik, J. Am. Chem. Soc. $10 \frac{2}{2}, 5033$ (1980).

36. R. Gygax, J. Wirz, J.T. Sprague, and N.L. Allinger, Helv. Chim. Acta 60, 2522 (1977).

37. R.H. Meisinger, Ph.D. Thesis, The Ohio State University, 1973.

38. M.A. Frish, C. Barker, J.L. Margrave, and M.S. Newman, J. Am. Chem. Soc. 85, 2356 (1963); H.A. Karnes, B.D. Kybett, M.H. Wilson, J.L. Margrave, and M.S. Newman, ibid. 87, 5554 (1965).

39. L.E. Salisbury, J. Org. Chem. 43, 4987, 4991 (1978).

40. H.A. Jahn and E. Teller, Proc. Roy. Soc., London, Ser. A 161, 220 (1937).

41. M.J.S. Dewar and G.J. Gleicher, J. Am. Chem. Soc. 87, 685 (1965). 